\title{
LIFE AND LITERATURE
}

\author{
in the Roman Republic
}

\begin{abstract}
"This book grew out of an effort to visualize a few of the early Roman writers in their response to their own environment. My generation was brought up to look upon the Roman as a kind of double-faced herm. In the senate-house, in the Forum, in the fields of jurisprudence and administration, the Roman revealed daring, versatility, imagination, and even philosophical penetration, whereas in literary expression, we were told, he was utterly imitative. The picture was not very convincing. Have we misread the modern connotations of the term 'imitation'? Have we neglected to penetrate the fog of concealing centuries in to the active, pulsating life of Roman men and women, and pursued instead the easier task of detecting parallels?" - TENNEY FranK
\end{abstract}





\section{TEN NEY FRANK}

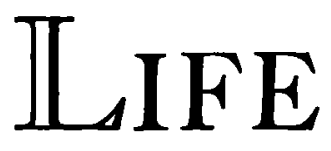

A N D

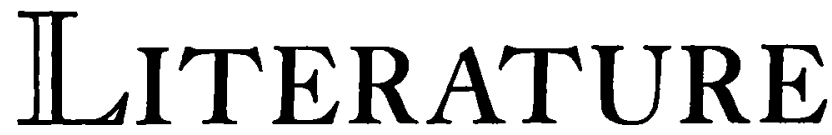

IN THE ROMAN REPUBLIC

U N I V E R S I T Y O F C A L I F O R N I A P R E S S

BER E E E Y A N D L OS A N GELES I 965 


\author{
University of California Press \\ Berkeley and Los Angeles, California \\ Cambridge University Press \\ London, England
}

Copyright, 1930, by

The Regents of the University of California

Originally published as Volume Seven of the Sather Classical Lectures

Fifth printing, 1965

(First Paper-bound Edition, Fourth printing)

PRINTED IN THE UNITED STATES OF AMERICA 